\title{
Should the contribution of ACE gene polymorphism to left ventricular hypertrophy be reconsidered?
}

Why some individuals and not others develop left ventricular hypertrophy (LVH) in the face of hypertension remains a mystery. What is certain is that none of us would wish to develop it ourselves. Even among asymptomatic normotensives with $\mathrm{LVH}$, not only are cardiac morbidity and mortality raised, but so too are the risks of suffering coronary, peripheral, or cerebrovascular disease. ${ }^{1}$ And herein lies a second mystery; why should a thicker left ventricular wall predispose to increased risk of coronary or cerebrovascular disease? Evidently, understanding the mechanisms regulating myocardial growth might shed light on the pathophysiology of the hypertensive state, leading to new therapeutic strategies.

\section{Myocardial tissue renin-angiotensin systems and myocardial growth}

Most of us are familiar with the role of the circulating or endocrine renin-angiotensin system in the control of circulating blood volume and blood pressure. Fewer will be familiar with the recognised role of local renin-angiotensin systems in controlling growth responses in diverse tissues. Could they be performing this function in the mammalian heart? Certainly, renin-angiotensin system components are synthesised locally in LV tissue, and such synthesis is upregulated during ventricular growth. ${ }^{2}$ Angiotensin converting enzyme (ACE) inhibitors may be more effective than other agents at causing regression of hypertensive LVH, and may achieve this (as they do in animal models) without effect on blood pressure ${ }^{3}$; but how could such a role for the myocardial renin-angiotensin system activity be further investigated? After all, left ventricular myocardial tissue cannot routinely be obtained for quantitative assessment of renin-angiotensin system gene expression.

In 1990, Rigat et al offered a way around this impasse. ${ }^{4}$ $\mathrm{He}$ described a polymorphism of the human ACE gene consisting of the presence (insertion, I allele) or absence (deletion, D allele) of a 287 base pair fragment. The D allele was associated with higher circulating ${ }^{4}$ and myocardial ACE concentrations. ${ }^{5}$ If the myocardial tissue reninangiotensin system was a key regulator of $\mathrm{LVH}$, then the $\mathrm{D}$ allele ought to be associated with greater LV mass.

Sadly, if the hypothesis was straightforward, the results were not. An initial wave of enthusiasm was rapidly followed by a wave of scorn.

\section{Lack of association of ACE I/D genotype with LV mass}

On the face of it, the report by Hamon and colleagues in this issue ${ }^{6}$ adds another nail to the coffin. In accord with a number of similar studies, no association between ACE genotype and LV mass was identified among 141 white patients with normal coronary arteries. Following a similar report by Lindpaintner et $a l,{ }^{7}$ who studied 2439 individuals, it would seem hard to exhume the hypothesis.

Investigating the influence of a gene on a phenotypic trait, however, can be a tricky business. Only in the simplest of cases can polymorphisms be readily associated with phenotype. If the number of fingers were coded for by one gene, the association of a polymorphism with the presence of six fingers on each hand would be easy to spot-a rare phenotypic trait is easily associated with a rare allelic variant. But what if the phenotypic trait was a continuous rather than a discrete variable, if the polymorphism was common and accounted for only part of the phenotypic variation, and if phenotype was also strongly influenced by environment? The situation would be further confused if carriage of the polymorphism increased mortality, and study design would be hampered if the strength of influence of the polymorphism on phenotype was unknown.

All of these problems apply to the ACE gene I/D polymorphism. The polymorphism is ubiquitous (the genotypes II, ID, and DD divided roughly $1: 2: 1$ ); LV mass is a continuous variable, under the influence of a large number of environmental and biological effects (for example, exercise, age, sex, blood pressure burden, race); the polymorphism may be associated with excess mortality (from ischaemic heart disease ${ }^{8}$ or cardiomyopathy), as is its presumed associated phenotypic trait $(\mathrm{LVH})^{1}$; and the strength of influence of the polymorphism on LV mass is unquantified.

To identify an effect of a polymorphism such as this on phenotype would require a highly homogeneous young population, and minimal and quantifiable exposure to environmental influences on phenotype. A very large (and unpredictable, given the unknown strength of gene effect) number of subjects would be required, especially as ACE genotype accounts for only half of the variance in serum ACE concentrations ${ }^{4}$; even if $\mathrm{LV}$ mass were linearly related to ACE concentrations, there would not be a perfect correlation between LV mass and ACE genotype. To date, no published study has met these criteria.

Hamon and colleagues' study, like others before, ${ }^{9}$ may be too small to detect an influence on $\mathrm{LV}$ mass. Nonetheless, a very powerful influence of ACE genotype on LV mass might be detectable in a highly uniform study population missing from these studies. Hamon et al, like others, ${ }^{7}$ studied a group of mixed sex $(67 \%$ male $)$ and diverse age (53 \pm 10 years) among whom lifelong physiological effects on LV mass are unlikely to have been uniform, and which are not quantifiable. Nearly half (46\%) the subjects suffered hypertension (or were treated for it, some with blood pressures of $>160 / 95 \mathrm{~mm} \mathrm{Hg}$ ), the duration, severity, and influence of which is unknown. 
Further, between $28 \%$ and $61 \%$ were receiving treatment of unknown duration with antihypertensive medications known have an effect on LV mass. Indeed, $12 \%$ were taking inhibitors of the gene product under investigation (namely, ACE inhibitors). These problems are not unique: between $12 \%$ and $16 \%$ of each genotype studied by Lindpaintner $e t \mathrm{al}^{7}$ were similarly medicated. In studies of trait analysis, it is not possible to make any meaningful allowance for the influence of such factors on LV mass. Finally, lack of racial homogeneity in some studies might further hinder detection of a genotype-phenotype association. Both propensity to develop LVH (greater among blacks) and association between ACE genotype and ACE concentrations (perhaps low or absent among blacks) ${ }^{10}$ differs by race. Racial differences might partly account for the negative findings of Hamon and colleagues (using a white population), the negative findings of Lindpaintner $e t$ al (using mixed races), ${ }^{7}$ and the positive findings of Iwai $e t$ al (in a Japanese group). ${ }^{11}$

All of these studies may have been prone to skew from several opposing factors: deaths attributable to the genotype or to LVH itself ${ }^{1}$ may have "filtered out" cases in which the $\mathrm{D}$ allele was most strongly associated with LVH; in contrast, the effect of hypertension on LV mass might be amplified among those with the DD genotype ${ }^{12}$; together, these factors would tend to increase study "white noise", as would well recognised technical problems causing misclassification of some heterozygote subjects as being homozygote for the $\mathrm{D}$ allele. ${ }^{13}$

\section{Are reports of the hypothesis's death premature?}

Perhaps we have all been trying to answer the wrong question. The issue, perhaps, is not whether the $\mathrm{D}$ polymorphism of the ACE gene is "the gene for LVH". LVH is not a discrete phenotypic characteristic due solely to the presence of one gene. In fact, LV mass is a continuous variable and is generally a manifestation of an interaction between physiological stimuli (such as increased cardiac work) and a transducing system (possibly renin-angiotensin). Crosssectional population-based studies may not be the most appropriate way to investigate such mechanistic issues. If myocardial tissue renin-angiotensin system transduces a growth stimulus, it is scarcely surprising that small studies of individuals exposed to minimal (and varied) growth stimuli fail to show an association of ACE genotype with LV mass. Neither is it a surprise that very large studies of heterogeneous samples exposed to diverse and unquantifiable growth stimuli generate sufficient white noise to mask any possible genotype associations. Comparative studies of individuals matched for ACE genotype, with one group exposed to an LV growth stimulus such as hypertension or physical training, or prospective studies of individuals of defined genotype in whom LV growth is anticipated are required.

As a "second best", one might examine studies that have included large numbers of individuals exposed to another genetic or environmental LV growth stimulus. Such stimuli, one might hypothesise, would be transduced more in those with increasing numbers of $\mathrm{D}$ alleles. From such studies comes the suggestion that ACE genotype might indeed be influencing LV mass. Among 183 patients with hypertrophic cardiomyopathy, DD genotype was associated with greater LV mass. ${ }^{14} \mathrm{D}$ allele frequency was also higher among those with evidence of hypertrophic cardiomyopathy than in unaffected siblings. ${ }^{15}$ The association of systolic blood pressure with LV mass might be stronger in those of DD genotype. ${ }^{12}$ Finally, the D allele was more frequent among hypertensives and nor- motensives with ECG criteria for LVH than in those without. ${ }^{11}{ }^{16}$ An association of ACE genotype with LV mass has been identified in a population containing larger numbers of untreated hypertensives, ${ }^{11}$ and DD genotype was associated with increased concentric remodelling in untreated patients referred for investigation of suspected arterial hypertension. ${ }^{17}$

Although the place of the ACE gene I/D polymorphism is unclear, largely because of the lack of appropriate studies, the likely importance of tissue renin-angiotensin systems in the control of myocardial growth remains. Further investigation may yet have much to offer. Why a thicker LV wall should be associated with an increased risk of coronary or cerebrovascular disease is another mystery. Reports linking ACE genotype (as a marker of tissue renin-angiotensin system activity) with risk of myocardial infarction, ${ }^{8}$ development of LVH and thickening of the common carotid arterial wall, ${ }^{18}$ might provide one explanation.

Research Fellow, Hatter Institute for Cardiovascular Studies,

HUGH MONTGOMERY

Department of Cardiology,

University College Hospital,

Grafton Way, London WC1E 6DB,

United Kingdom

1 Levy D, Garrison R, Savage D, Kannel W, Castelli W. Prognostic implications of echocardiographically determined left ventricular mass in the Framingham Heart Study. $N$ Engl $₹$ Med 1990;322:1561-6.

2 Schunkert H, Dzau VJ, Tang SS, Hirsch AT, Apstein CS, Lorell BH Increased rat cardiac angiotensin converting enzyme activity and mRNA expression in pressure overload left ventricular hypertrophy: effects on coronary resistance, contractility, and relaxation. $\mathcal{F}$ Clin Invest 1990;86: 1913-20

3 Lievre M, Gueret P, Gayet C, Roudaut R, Haugh MC, Delair S, et al. Ramipril-induced regression of left ventricular hypertrophy in treated hypertensive individuals. Hypertension 1995;25:92-7.

4 Rigat B, Hubert C, Alhenc-Gelas F, Cambien F, Corvol P, Soubrier F. An insertion/deletion polymorphism in the angiotensin-1-converting enzyme gene accounting for half the variance of serum enzyme levels. $f$ Clin Invest 1990;86:1343-6.

5 Jan Danser AH, Schalekamp MADH, Bax WA, Van Den Brink AM, Saxena PR, Riegger GAJ, et al. Angiotensin-converting enzyme in the human heart. Effect of the deletion/insertion polymorphism. Circulation 1995;92:1387-8.

6 Hamon M, Amant C, Bauters C, Richard F, Helbecque N, Mc Faden E, $e$ al. Association of angiotensin converting enzyme and angiotensin II type 1 receptor genotypes with left ventricular function and mass in patients with angiographically normal coronary arteries. Heart 1997;77:502-5.

7 Lindpaintner K, Lee M, Larson MG, Rao VS, Pfeffer MA, Ordovas JM, $e$ $a l$. Absence of association of genetic linkage between the angiotensin converting-enzyme gene and left ventricular mass. N Engl $f$ Med 1996 334:1023-8.

8 Cambien F, Poirer O, Lecerf L, Evans A, Cambou J-P, Arveiler D, et al. Deletion polymorphism in the gene for angiotensin-converting enzyme is a potent risk factor for myocardial infarction. Nature 1992;359:641-4.

9 Kupari M, Perola M, Koskinen P, Virolainen J, Karhunen P. Left ventricular size, mass, and function in relation to angiotensin-converting enzyme lar size, mass, and function in relation to angiotensin-converting en
gene polymorphism in humans. Am $\mathcal{F}$ Physiol' $1994 ; 267: \mathrm{H} 107-11$.

10 Bloem LJ, Manatunga AK, Pratt JH. Racial difference in the relationship of an angiotensin I-converting enzyme gene polymorphism to serum angiotensin I-converting enzyme activity. Hypertension 1996;27:62-6.

11 Iwai N, Nakamura Y, Ohmichi N, Kinoshita M. The DD genotype of the angiotensin converting enzyme is a risk factor for left ventricular hypertrophy. Circulation 1994;90:2622-8.

12 Prasad N, O'Kane KP, Johnstone HA, Wheeldon NM, McMahon AD Webb DJ, et al. The relationship between blood pressure and left ventricular mass in essential hypertension is observed only in the presence of the angiotensin-converting enzyme gene deletion allele. $Q \mathcal{F M} 1994 ; 87$ 659-62.

13 Shanmugam V, Sell KW, Saha BK. Mistyping ACE heterozygotes. PCR Methods and Applications 1993;3:120-1.

14 Lechin M, Quinones MA, Omran A, Hill R, Yu Q-T, Rakowski H, et al. Angiotensin-1 converting enzyme genotypes and left ventricular hypertrophy in patients with hypertrophic cardiomyopathy. Circulation 1995;92:1808-13.

15 Marian AJ, Yu Q, Workman R, Greve E, Roberts R. Angiotensin-converting enzyme polymorphism in hypertrophic cardiomyopathy and sudden cardiac death. Lancet 1993;342:1085-6.

16 Schunkert H, Hense H-W, Holmer SR, Stender M, Keil U, Lorell BH, et al. Association between a deletion polymorphism of the angiotensin-converting-enzyme gene and left ventricular hypertrophy. $N$ Engl $\mathcal{F}$ Med 1994;330:1634-8.

17 Gharavi AG, Lipkowitz MS, Diamond JA, Jhang JS, Phillips RA. Deletion polymorphism of the angiotensin-converting enzyme gene is independently associated with left ventricular mass and geome

18 Castellano M, Muiesan L, Rizzoni D, Beschi M, Pasini G, Cinelli A, et al Angiotensin-converting enzili Angiotensin-converting enzyme I/D polymorphism and arterial wall 91:2721-4. 